Биополимеры растений

УДК 62-664.2:662.312.4

\title{
СРАВНЕНИЕ МЕТОДОВ РАСЧЕТА ТЕПЛОТЫ СГОРАНИЯ БИОПОЛИМЕРОВ
}

\author{
(C) М.Я. Иоелович \\ Designer Energy Ltd, Rehovot 76100 (Israel), e-mail: bd895892@zahav.net.il
}

В данной работе были проанализированы различные методы расчета высшей (Q) и низшей (q) теплоты сгорания для биополимеров растений (лигнин, целлюлоза, гемицеллюлозы, крахмал, пектин, белки) и некоторых других компонентов биомассы (смоляные кислоты, липиды и др.). Результаты исследований показали, что расчеты с использованием $\mathrm{E}_{\mathrm{q}}$-параметра (т.е. энергии сгорания, приходящейся на 1 г $\mathrm{O}_{2}$ ) дают отклонение от экспериментальных значений около $4 \%$ для Q и более чем 7\% для q. В случае расчетов, основанных на вкладе структурных групп полимеров, отклонение составляет в среднем $3 \%$. Самое низкое отклонение от экспериментальных данных, около $0,5 \%$ для Q и менее $1 \%$ для q, было получено с использованием усовершенствованного способа расчета, который основан на определении элементного состава биополимеров и других компонентов биомассы. Расчеты теплот сгорания для образцов биомассы с помощью предлагаемого усовершенствованного метода были очень близки к экспериментальным значениям теплотворной способности. Было установлено, что наиболее предпочтительным способом утилизации отходов является сжигание гранул, состоящих из отходов растительной биомассы и полиолефинов, поскольку такой способ сжигания обеспечивает более высокую теплотворную способность и повышенную плотность тепловой энергии, чем отдельное сжигание лишь биомассы, и сопровождается меньшим количеством углекислого газа по сравнению с отдельным сжиганием лишь отходов полиолефинов.

Ключевые слова: биополимеры, биомасса, химическое строение, элементный состав, композиция, теплота сгорания; методы расчета, калориметрия.

\section{Введение}

Человечество производит огромное количество твердых отходов, в том числе несколько миллиардов тонн отходов растительной биомассы (опилки, стружки, ветки, солома, шелуха, бумага, картон, текстиль, и т.п.) и сотни миллионов тонн отходов пластмасс в год [1]. В настоящее время в экономически слабо развитых и развивающихся странах отходы растительной биомассы являются основным источником тепловой энергии для бытовых нужд. В странах с высокоразвитой экономикой значительную часть твердых органических отходов также сжигают для получения тепловой энергии [2]. Это требует проведения предварительной оценки теплотворной способности различных видов растительной биомассы и ее отходов.

Для экспериментального определения удельной энергии или энтальпии сгорания органических веществ и материалов необходимо использовать специальные высокоточные, но сложные и дорогие установки - кислородные бомбы, снабженные калориметрами. Кроме того, экспериментальное определение теплот сгорания является продолжительной процедурой и требует введения различных поправок и проведения трудоемких расчетов. Поэтому для предварительной оценки теплотворной способности горючих отходов используются приближенные методы расчета теплотворной способности.

В детальном обзоре [3] для расчета теплоты сгорания различных видов растительной биомассы предложены более сотни уравнений, основанных на определении элементного состава, содержания летучих веществ, фиксированного углерода, золы, компонентного состава биомассы или ее физических характеристик. К сожалению, в этом обзоре не дается критического анализа различных математических моделей, поэтому невозможно выделить уравнения, наиболее подходящие для конкретных видов биомассы. Поскольку число видов растительной биомассы неограниченно, то и число корреляционных уравнений также может быть неограниченным. Вследствие этого задача нахождения наилучшего корреляционного

Иоелович Михаил Яковлевич - доктор химических наук, професcop, e-mail: bd895892@zahav.net.il уравнения, позволяющего рассчитывать теплоту сгорания различных биомасс, становится трудно выполнимой. Дополнительная проблема состоит 
в том, что экспериментальное определение многочисленных параметров корреляционных уравнений выполняется с определенными погрешностями, которые, складываясь, увеличивают погрешность конечных расчетов теплоты сгорания. Кроме того, определение этих параметров для образцов биомассы требует времени и использования специальной аппаратуры.

Вследствие отмеченных трудностей известных математических моделей в данной работе для расчета теплоты сгорания образцов биомассы предлагается другой подход. Растительная биомасса, как известно, представляет собой комплекс природных биополимеров, таких как целлюлоза (целл), гемицеллюлозы (геми), крахмал, пектин, лигнин, белки, а также экстрактивных (экстр) и некоторых других веществ. Таким образом, чтобы оценить теплотворную способность биомассы с определенным композиционным составом, достаточно рассчитать теплоту сгорания ограниченного числа ее основных компонентов - биополимеров и некоторых других веществ. С этой целью было использовано универсальное уравнение Менделеева [4, 5], а также уравнения других исследователей [6], предназначенные для расчета теплотворной способности любых видов органических веществ и материалов с известным элементным составом.

Кроме того, для большого числа синтетических полимеров было установлено, что низшая тепловая энергия сгорания (Eq, кДж), приходящаяся на 1 г $\mathrm{O}_{2}$, является величиной постоянной, составляющей $\mathrm{Eq}=13,1$ кДж на 1 г $\mathrm{O}_{2}[7,8]$. Тогда низшая теплота сгорания (q, кДж/г) полимера может быть рассчитана по уравнению:

$$
\mathrm{q}=\mathrm{E}_{\mathrm{q}} \mathrm{n}_{\mathrm{O}_{2}} \mathrm{M}_{\mathrm{O}_{2}} / \mathrm{M}_{\mathrm{p}}
$$

где $\mathrm{M}_{\mathrm{O}_{2}}=32$ молекулярная масса $\mathrm{O}_{2} ; \mathrm{n}_{\mathrm{O}_{2}}$ - число молей $\mathrm{O}_{2}$, расходуемых для полного сгорания одного моля звена полимера с молекулярной массой $\mathrm{M}_{\mathrm{p}}$.

Для расчета теплоты сгорания биополимеров был использован также метод, основанный на инкрементах структурных групп полимеров [9].

Конечной целью данного исследования было проведение сравнительного анализа различных методов расчета теплот сгорания биополимеров, чтобы выбрать из них наиболее точный и надежный метод.

\section{Экспериментальная часть}

Maтериаль. Были исследованы образцы биополимеров и некоторых других органических веществ растительной биомассы (табл. 1).

Образцы пектина, крахмала, ксилана и абиетиновой кислоты были получены из компании SigmaAldrich, а образец хлопковой целлюлозы высокой чистоты (chemical grade) - из компании Hercules. Maннан экстрагировали из молотой древесины ели [10]. Лигнины изолировали из древесины стандартным методом TAPPI T222 оm-02. Глютен выделяли из клейковины пшеницы по методике [11]. Суберин экстрагировали из коры осины раствором метилата натрия в метаноле [12]. Элементный состав образцов рассчитывали на основе химической формулы вещества и его молекулярной массы (табл. 1, 2).

Кроме того, объектами исследования являлись также образцы биомассы, полученные из компании Petrobras (Бразилия). Композиционный состав этих образцов (табл. 3) определяли стандартизированными методами химического анализа NREL [13].

Таблица 1. Список использованных компонентов растений и их основные характеристики

\begin{tabular}{l|c|c|c|c}
\hline \multicolumn{1}{c|}{ Образец } & Аббревиатура & Формула звена & $\mathrm{M}_{\mathrm{p}}$ & $\mathrm{n}\left(\mathrm{O}_{2}\right)$ \\
\hline Глютен пшеницы & $\mathrm{GLT}$ & $\mathrm{C}_{5} \mathrm{H}_{6} \mathrm{O}_{2} \mathrm{~N}$ & 112 & 5,5 \\
Ксилан березы & $\mathrm{XYL}$ & $\mathrm{C}_{5} \mathrm{H}_{8} \mathrm{O}_{4}$ & 132 & 5 \\
Маннан ели & $\mathrm{MAN}$ & $\mathrm{C}_{6} \mathrm{H}_{10} \mathrm{O}_{5}$ & 162 & 6 \\
Целлюлоза хлопковая & $\mathrm{CEL}$ & $\mathrm{C}_{6} \mathrm{H}_{10} \mathrm{O}_{5}$ & 162 & 6 \\
Крахмал кукурузный & $\mathrm{C} \mathrm{C}_{6} \mathrm{H}_{10} \mathrm{O}_{5}$ & 162 & 6 \\
Пектин цитрусовый & $\mathrm{STR}$ & $\mathrm{C}_{6} \mathrm{H}_{8} \mathrm{O}_{6}$ & 176 & 5 \\
Лигнин ели & $\mathrm{PEC}$ & $\mathrm{C}_{10} \mathrm{H}_{11} \mathrm{O}_{3}$ & 179 & 11,25 \\
Лигнин осины & $\mathrm{LIG-S}$ & $\mathrm{C}_{11} \mathrm{H}_{12} \mathrm{O}_{4}$ & 208 & 12 \\
Абиетиновая кислота & $\mathrm{LIG-A}$ & $\mathrm{C}_{20} \mathrm{H}_{30} \mathrm{O}_{2}$ & 302 & 26,5 \\
Суберин из коры осины & $\mathrm{ABA}$ & $\mathrm{C}_{72} \mathrm{H}_{140} \mathrm{O}_{5}$ & 1084 & 104,5 \\
\hline
\end{tabular}


Таблица 2. Элементный состав образцов (масс. \%)

\begin{tabular}{c|c|c|c|c}
\hline Биомасса & $\mathrm{C}$ & $\mathrm{H}$ & $\mathrm{O}$ & $\mathrm{N}$ \\
\hline GLT & 53,6 & 5,3 & 28,6 & 12,5 \\
XYL & 45,5 & 6,0 & 48,5 & 0 \\
MAN & 44,5 & 6,1 & 49,4 & 0 \\
CEL & 44,5 & 6,1 & 49,4 & 0 \\
STR & 44,5 & 6,1 & 49,4 & 0 \\
PEC & 40,9 & 4,5 & 54,6 & 0 \\
LIG-S & 67,0 & 6,2 & 26,8 & 0 \\
LIG-A & 63,5 & 5,8 & 30,7 & 0 \\
ABA & 79,5 & 9,9 & 10,6 & 0 \\
SUB & 79,7 & 13,0 & 7,3 & 0 \\
\hline
\end{tabular}

Таблица 3. Композиционный состав образцов биомассы ( $\mathrm{w}_{\mathrm{i}}$, масс. доли)

\begin{tabular}{l|c|c|c|c|c|c}
\hline \multicolumn{1}{c|}{ Биомасса } & Аббр & Целл & Геми & Лигнин & Экстр & Зола \\
\hline Опилки хвойной древесины & SW & 0,48 & 0,20 & 0,28 & 0,02 & 0,02 \\
Опилки лиственной древесины & HW & 0,45 & 0,25 & 0,23 & 0,03 \\
Багасса & BA & 0,40 & 0,31 & 0,20 & 0,03 \\
Стебли кукурузы & $\mathrm{CS}$ & 0,38 & 0,33 & 0,20 & 0,02 \\
Картон & $\mathrm{CB}$ & 0,60 & 0,12 & 0,18 & 0,06 \\
Оберточная бумага & $\mathrm{WP}$ & 0,73 & 0,07 & 0,05 & 0,07 \\
\hline
\end{tabular}

Memoдbl. Высшую теплоту сгорания (Q) исследованных образцов в сухом состоянии определяли с использованием кислородной бомбы из нержавеющей стали, снабженной изотермическим водяным калориметром, который обеспечивал определение температуры с точностью $\pm 0,001 \mathrm{~K}$. Процедура экспериментов подробно описана в работах $[14,15]$. Низшую теплоту сгорания образцов (q) рассчитывали с помощью уравнения [8]:

$$
\mathrm{q}(\kappa Д ж / г)=\mathrm{Q}(\kappa Д ж / г)-0,22 \mathrm{H},
$$

где Н - процентное содержание водорода в образце.

Стандартную погрешность изменений находили по известной формуле:

$$
S D=\sqrt{\sum\left(X_{i}-X_{a y}\right)^{2} /(n-1)}
$$

где $\mathrm{X}_{\mathrm{i}}$ и $\mathrm{X}_{\mathrm{av}}$ - измеряемое и среднее арифметическое значение теплоты сгорания соответственно; $\mathrm{n}-$ количество измерений для одного и того же образца.

Экспериментальные теплоты сгорания сравнивались со значениями теплот, рассчитанных различными методами:

- с помощью уравнений Менделеева (4), (5) [4, 5] и Парикха (6), (7) [6],

$$
\begin{gathered}
\mathrm{Q}(\text { кДж/г) }=0,339 \mathrm{C}+1,255 \mathrm{H}+0,109 \mathrm{~S}-0,109 \mathrm{O}-0,015 \mathrm{~N} ; \\
\mathrm{q}(\kappa Д ж / \Gamma)=\mathrm{Q}-0,226 \mathrm{H} ; \\
\mathrm{Q}(\text { кДж/г) }=0,349 \mathrm{C}+1,1783 \mathrm{H}+0,101 \mathrm{~S}-0,1034 \mathrm{O}-0,015 \mathrm{~N} ; \\
\mathrm{q} \mathrm{( \kappa Дж/г)}=\mathrm{Q}-0,202 \mathrm{H},
\end{gathered}
$$

где $\mathrm{C}, \mathrm{H}, \mathrm{O}, \mathrm{S}, \mathrm{N}$ - процентное содержание соответствующих атомов в сухом органическом веществе или материале;

- на основе, $\mathrm{E}_{\mathrm{q}}$-параметра (1) и (8) [7, 8],

$$
\mathrm{Q}=\mathrm{k} \mathrm{E}_{\mathrm{q}} \mathrm{n}_{\mathrm{O}_{2}} \mathrm{M}_{\mathrm{O}_{2}} / \mathrm{M}_{\mathrm{p}}
$$

где $\mathrm{k} \approx 1,075$ - коэффициент перехода от низшей к высшей теплоте сгорания;

- на основе инкрементов структурных групп (табл. 4). 
Таблица 4. Инкременты структурных групп полимеров в высшую теплоту сгорания [9]

\begin{tabular}{c|c||c|c}
\hline Группа & $\mathrm{Q}_{\mathrm{i}}$, кДж/моль, групп & Группа & $\mathrm{Q}_{\mathrm{i}}$, кДж/моль, групп \\
\hline$-\mathrm{CH}_{3}$ & 775 & $-\mathrm{COO}-$ & 112 \\
$-\mathrm{CH}_{2}-$ & 670 & $-\mathrm{C}=\mathrm{O}$ & 259 \\
$-\mathrm{CH}-$ & 518 & $-\mathrm{NH}-$ & 77 \\
$-\mathrm{C}-$ & 431 & $-\mathrm{O}-$ & -132 \\
$-\mathrm{H}$ & 190 & $-\mathrm{OH}$ & -108 \\
\hline
\end{tabular}

Высшую теплоту сгорания рассчитывали по уравнению:

$$
\mathrm{Q}(\kappa Д ж / \Gamma)=\mathrm{M}_{\mathrm{p}}^{-1} \Sigma \mathrm{n}_{\mathrm{i}} \mathrm{Q}_{\mathrm{i}} \text {. }
$$

Затем рассчитывали низшую теплоту сгорания:

$$
\mathrm{q}(\kappa Д ж / \Gamma)=\mathrm{Q}(\kappa Д ж / г)-0,219 \mathrm{H} .
$$

Среднее относительное отклонение расчетных значений от экспериментальных находили по формуле:

$$
\mathrm{RD}(\%)=100 \Sigma\left(\mathrm{ASD} / \mathrm{X}_{\mathrm{e}}\right) / \mathrm{n} \text {. }
$$

ASD - среднее стандартное отклонение: $\mathrm{ASD}=\sqrt{\Sigma\left(\mathrm{X}_{\mathrm{c}}-\mathrm{X}_{e}\right)^{2} /(\mathrm{n}-1)}$,

где $\mathrm{X}_{\mathrm{c}}$ и $\mathrm{X}_{\mathrm{e}}$ - рассчитанное и экспериментальное значение теплоты сгорания соответственно; $\mathrm{n}-$ число образцов.

\section{Результаты и их обсуждение}

Экспериментальные результаты определения теплот сгорания исследованных биополимеров и других компонентов растений приведены в таблице 5 .

Установленные значения теплот сгорания некоторых биополимеров, например целлюлозы и крахмала, согласуются с результатами, полученными ранее в работах [14-16].

Экспериментальные значения теплот сгорания (ЕХР) были сопоставлены с результатами расчетов с использованием различных методов (табл. 6,7$)$.

Таблица 5. Результаты определения высшей $(\mathrm{Q})$ и низшей (q) теплот сгорания

\begin{tabular}{c|c|c}
\hline Образец & $\mathrm{Q}$, кДж/г & $\mathrm{q}$, кДж/г \\
\hline PEC & $13,73 \pm 0,16$ & $12,76 \pm 0,15$ \\
XYL & $17,80 \pm 0,25$ & $16,38 \pm 0,23$ \\
STR & $17,53 \pm 0,18$ & $16,23 \pm 0,17$ \\
MAN & $17,50 \pm 0,21$ & $16,20 \pm 0,19$ \\
CEL & $17,45 \pm 0,12$ & $16,12 \pm 0,11$ \\
GLT & $21,87 \pm 0,28$ & $20,64 \pm 0,26$ \\
LIG-S & $27,94 \pm 0,37$ & $26,45 \pm 0,36$ \\
LIG-A & $26,12 \pm 0,34$ & $24,83 \pm 0,32$ \\
ABA & $38,25 \pm 0,25$ & $36,17 \pm 0,24$ \\
SUB & $42,56 \pm 0,28$ & $39,20 \pm 0,26$ \\
\hline
\end{tabular}

Таблица 6. Сравнение экспериментальных и расчетных результатов определения высших теплот сгорания $(\mathrm{Q}$, кДж/г)

\begin{tabular}{c|c|c|c|c|c|c}
\hline Образец & EXP & Ур. (4) & Уp. (6) & Уp. (8) & Уp. (9) & Уp. (12) \\
\hline PEC & 13,73 & 13,56 & 13,93 & 12,80 & 13,70 & 13,75 \\
XYL & 17,80 & 17,67 & 17,90 & 17,07 & 17,14 & 17,81 \\
STR & 17,53 & 17,36 & 17,61 & 16,69 & 16,49 & 17,50 \\
MAN & 17,50 & 17,36 & 17,61 & 16,69 & 16,49 & 17,50 \\
CEL & 17,45 & 17,36 & 17,61 & 16,69 & 16,49 & 17,50 \\
GLT & 21,87 & 21,52 & 21,81 & 22,12 & 21,90 & 21,70 \\
LIG-S & 27,94 & 27,57 & 27,91 & 28,32 & 27,71 & 27,75 \\
LIG-A & 26,12 & 25,46 & 25,82 & 25,99 & 26,38 & 26,05 \\
ABA & 38,25 & 38,22 & 38,31 & 39,54 & 38,38 & 38,27 \\
SUB & 42,56 & 42,54 & 42,38 & 43,44 & 42,52 & 42,46 \\
RD, \% & 0 & 1,4 & 0,8 & 3,9 & 2,8 & 0,5 \\
\hline
\end{tabular}


Таблица 7. Сравнение экспериментальных и расчетных результатов определения низших теплот сгорания $(\mathrm{q}, \mathrm{\kappa}$ Дж/г)

\begin{tabular}{c|c|c|c|c|c|c}
\hline Образец & EXP & Ур. (5) & Ур. (7) & Ур. (1) & Уp. (10) & Уp. (13) \\
\hline PEC & 12,76 & 12,54 & 13,00 & 11,91 & 12,71 & 12,81 \\
XYL & 16,38 & 16,31 & 16,72 & 15,88 & 15,80 & 16,45 \\
STR & 16,23 & 16,00 & 16,38 & 15,52 & 15,18 & 16,18 \\
MAN & 16,20 & 16,00 & 16,38 & 15,52 & 15,18 & 16,18 \\
CEL & 16,12 & 16,00 & 16,38 & 15,52 & 15,18 & 16,18 \\
GLT & 20,64 & 20,32 & 20,73 & 24,33 & 20,71 & 20,61 \\
LIG-S & 26,45 & 26,17 & 26,67 & 26,35 & 26,34 & 26,60 \\
LIG-A & 24,83 & 24,15 & 24,65 & 24,18 & 25,10 & 24,79 \\
ABA & 36,17 & 36,00 & 36,30 & 36,78 & 36,30 & 36,19 \\
SUB & 39,20 & 39,60 & 39,75 & 40,41 & 39,72 & 39,70 \\
RD, $\%$ & 0 & 1,7 & 1,4 & 7,2 & 3,2 & 0,9 \\
\hline
\end{tabular}

Анализ полученных результатов показал, что расчеты по уравнениям (1) и (8) с использованием $\mathrm{E}_{\mathrm{q}}$ параметра является недостаточно точным и надежным, поскольку этот метод расчета дает отклонение от экспериментальных значений около 4\% для Q и более чем 7\% для q. В случае расчетов, основанных на вкладе структурных групп (9), (10), отклонение составляет около 3\%. Расчеты по методу Менделеева (4), (5) дали заниженные, а по методу Парикха (6), (7) - завышенные результаты по сравнению с экспериментальными.

В данной работе для повышения точности расчетов были использованы уточненные значения вкладов элементов в теплоты сгорания и предложены следующие усовершенствованные расчетные уравнения:

$$
\begin{gathered}
\mathrm{Q}(\mathrm{MJ} / \mathrm{kg})=0,344 \mathrm{C}+1,217 \mathrm{H}+0,105 \mathrm{~S}-0,106 \mathrm{O}-0,015 \mathrm{~N} ; \\
\mathrm{q}(\mathrm{MJ} / \mathrm{kg})=\mathrm{Q}-0,210 \mathrm{H},
\end{gathered}
$$

где C, H, O, S, N - процентное содержание соответствующих атомов в сухом органическом материале.

Использование усовершенствованного способа расчета позволило получить наиболее низкое отклонение от экспериментальных результатов - до 0,5\% для Q и $0,9 \%$ для q.

Расчеты теплот сгорания образцов биомассы проводили с помощью уравнений:

$$
\begin{gathered}
\mathrm{Q}=\Sigma \mathrm{w}_{\mathrm{i}} \mathrm{Q}_{\mathrm{i}} \\
\mathrm{q}=\Sigma \mathrm{w}_{\mathrm{i}} \mathrm{q}_{\mathrm{i}},
\end{gathered}
$$

где $\mathrm{Q}_{\mathrm{i}}$ и $\mathrm{q}_{\mathrm{i}}$ - теплоты сгорания компонентов биомассы: целлюлозы, гемицеллюлоз, лигнина и экстрактивных веществ, например, АВА, рассчитанные с помощью усовершенствованного метода; $\mathrm{w}_{\mathrm{i}}-$ массовая доля соответствующих компонентов в сухой биомассе (табл. 3 ).

Рассчитанные по уравнениям (14) и (15) значения теплот сгорания (CALC) образцов биомассы были близки к экспериментальным теплотам сгорания (ЕXP) в пределах 1-1,2\% (табл. 8).

Таблица 8. Сравнение экспериментальных (EXP) и расчетных (CALC) значений теплот сгорания образцов биомассы

\begin{tabular}{c|c|c|c|c}
\hline \multirow{2}{*}{ Биомасса } & \multicolumn{2}{|c|}{ Q, кДж/г } & \multicolumn{2}{|c}{ q, кД/г } \\
\cline { 2 - 5 } & EXP & CALC & EXP & CALC \\
\hline SW & 20,45 & 20,53 & 19,11 & 19,19 \\
HW & 19,70 & 19,44 & 18,35 & 18,14 \\
BA & 19,00 & 18,84 & 17,82 & 17,60 \\
CS & 18,37 & 18,46 & 17,45 & 17,58 \\
CB & 18,48 & 16,54 & 15,56 & 17,55 \\
WP & 16,69 & 1,0 & 0 & 15,38 \\
RD,\% & 0 & & 1,2 \\
\hline
\end{tabular}


Основной проблемой использования отходов биомассы в качестве твердого топлива является их относительно низкая теплотворная способность и плотность тепловой энергии. Одним из способов решения этой проблемы является получение смешанного твердого топлива в виде гранул, содержащего наряду с отходами биомассы также добавки широко распространенных отходов синтетических полимеров, таких как полиэтилен (РЕ) и полипропилен (РP) [1]. Использование гранулированного смешанного топлива позволяет, с одной стороны, освободить окружающую среду от твердых отходов, а с другой - обеспечивает более высокую теплотворную способность (q) и повышенную плотность тепловой энергии (DE) (табл. 9).

Кроме того, биомасса растений считается нейтральной к выделению углекислого газа в окружающую среду, поэтому сжигание смешанного топлива приводит к уменьшению выбросов двуокиси углерода вдвое по сравнению с отдельным сжиганием только пластиковых отходов.

Таблица 9. Характеристики гранулированных отходов биомассы и их смесей с отходами полиолефинов $(1: 1)$

\begin{tabular}{|c|c|c|c|}
\hline Образец & $\mathrm{q}, \mathrm{\kappa} Д ж / \Gamma$ & $\mathrm{DE}, \Gamma Д ж / \mathrm{M}^{3}$ & $\mathrm{CO}_{2}, \mathrm{M}^{3} / \mathrm{K} \Gamma$ \\
\hline SW & 19,1 & 11,5 & 0 \\
\hline SW/PE & 31,9 & 20,8 & 0,8 \\
\hline PE & 44,6 & 11,1 & 1,6 \\
\hline $\mathrm{CS}$ & 17,5 & 10,2 & 0 \\
\hline $\mathrm{CS} / \mathrm{PP}$ & 30,2 & 19,3 & 0,8 \\
\hline PP & 43,0 & 10,8 & 1,6 \\
\hline $\mathrm{CB}$ & 17,2 & 10,1 & 0 \\
\hline $\mathrm{CB} / \mathrm{PE}$ & 31,1 & 19,2 & 0,8 \\
\hline WP & 15,5 & 9,0 & 0 \\
\hline $\mathrm{WP} / \mathrm{PP}$ & 30,2 & 18,7 & 0,8 \\
\hline
\end{tabular}

\section{Выводы}

1. В данной работе был проведен сравнительный анализ различных методов расчета высшей и низшей теплоты сгорания биополимеров и некоторых других компонентов растений.

2. Установлено, что расчеты с использованием $\mathrm{E}_{\mathrm{q}}$-параметра являются недостаточно точными и надежными, поскольку этот метод расчета дает отклонение от экспериментальных значений около 4\% для Q и более чем 7\% для q. В случае расчетов, основанных на вкладе структурных групп, отклонение составляет около 3\%. Самое низкое отклонение, $0,5 \%$ для Q и $0,9 \%$ для q, было получено с использованием усовершенствованного способа расчета, который основан на определении элементного состава основных компонентов биомассы.

3. Расчеты теплот сгорания для образцов биомассы с помощью предлагаемого усовершенствованного метода были близки к экспериментальным значениям теплотворной способности в пределах 1-1,2\%. Было установлено, что наиболее предпочтительным способом утилизации отходов является сжигание гранул, состоящих из отходов растительной биомассы и полиолефинов, поскольку такой способ сжигания обеспечивает более высокую теплотворную способность и повышенную плотность тепловой энергии, чем отдельное сжигание лишь биомассы, и сопровождается меньшим количеством углекислого газа по сравнению с отдельным сжиганием лишь отходов полиолефинов.

\section{Список литературы}

1. Ioelovich M. Problems of solid biofuels made of plant biomass // Advance in Energy. 2014. Vol. 2. N 1. Pp. 15-20.

2. Energy recover from waste. Report of New Energy Co. [Electronic resource]. URL: http://www.newenergycorp.com.au/what-we-do/waste-hierarchy. New Energy, West Perth, 2016.

3. Vargas-Moreno J.M., Callejón-Ferrea A.J., Pérez-Alonsoa J., Velázquez-Martí B. A review of the mathematical models for predicting the heating value of biomass materials // Renewable and Sustainable Energy Reviews. 2012. Vol. 16. Pp. 3065-3083.

4. Suris A.L. Heat of combustion of liquid halogen-organic compounds // Chem. Pertol. Eng. 2007. Vol. 43. N 1-2. Pp. 20-21.

5. Максимук Ю.В., Крук В.С., Антонова 3.А., Пономарев Д.А., Сушкова А.В. Расчет теплоты сгорания древесного топлива по элементному составу // Лесной журнал. 2016. № 6. С. 110-121.

6. Parikh J., Channiwala S.A., Ghosal G.K. A correlation for calculating HHV from proximate analysis of solid fuels // Fuel. 2005. Vol. 84. Pp. 487-494. 
7. Huggett C. Estimation of rate of heat release by means of oxygen consumption measurements // Fire and Mater. 1980. Vol. 4. Pp. 61-65.

8. Babrauskas V. Heat Release in Fires. New York: Elsevier, 1992. Ch.8. Pp. 251-255.

9. Walters R.N., Lyon R.E., Hackett S.M. Heats of combustion of high-temperature polymers // Fire and Mater. 2000. Vol. 24. Pp. 1-13.

10. Willfor S., Sjoholm R., Laine C., Roslund M., Hemming J., Holmbom B. Characterization of water-soluble galactoglucomannans from Norway spruce wood and thermomechanical pulp // Carbohydrate Polym. 2003. Vol. 52. Рp. 175-187.

11. Дубцова Г.Н., Колпакова В.В., Нечаев П.П. Использование белковых продуктов из пшеницы в пищевых производствах. М., 1992. 40 с.

12. Holloway P.J. Some variations in the composition of the suberin from the cork layers of higher plants // Phytochemistry. 1983. Vol. 22. N 2. Pp. 495-502.

13. Sluiter J.B., Ruiz R.O., Scarlata C.J., Sluiter A.D., Templeton D.W. Compositional analysis of lignocellulosic feedstocks. Review and description of methods // J Agric. Food Chem. 2010. Vol. 58. N 16. Pp. 9043-9053.

14. Ioelovich M. Study of thermodynamic stability of various allomorphs of cellulose // J. Basic Appl. Res. Int. 2016. Vol. 16. N 2. Pp. 96-103.

15. Goldberg R.N., Schliesser J., Mittal A. A thermodynamic investigation of the cellulose allomorphs: cellulose(am), cellulose I $\beta$ (cr), cellulose II(cr), and cellulose III(cr) // J. Chem. Thermodyn. 2015. Vol. 81. Pp. 184-226.

16. Kabo G.J., Voitkevich O.V. Blokhin A.V. Thermodynamic properties of starch and glucose // J. Chem. Thermodyn. 2013. Vol. 59. Pp. 87-93.

Поступило в редакичию 4 декабря 2016 г.

После переработки 25 декабря 2016 г. 


\section{OPOLYMERS}

Ioelovich M.Ya. COMPARISON OF METHODS FOR THE CALCULATION OF HEAT OF COMBUSTION OF BI-

\section{Designer Energy Ltd, Rehovot 76100 (Israel), e-mail: bd895892@zahav.net.il}

In this paper, various methods for calculating the higher $(\mathrm{Q})$ and lower (q) calorific values for plant biopolymers (lignin, cellulose, hemicellulose, starch, pectin, proteins) and some other components of biomass (resin acids, lipids, ). The results of the studies showed that calculations using the $\mathrm{E}_{\mathrm{q}}$ parameter (i.e., the combustion energy per $1 \mathrm{~g}$ of $\mathrm{O}_{2}$ ) give a deviation from the experimental values of about $4 \%$ for $\mathrm{Q}$ and more than $7 \%$ for $\mathrm{q}$. In the case of calculations based on the contribution of structural groups of polymers, the deviation is on average 3\%. The lowest deviation from the experimental data, about $0,5 \%$ for $\mathrm{Q}$ and less than $1 \%$ for $\mathrm{q}$, was obtained using an improved calculation method that is based on determining the elemental composition of biopolymers and other biomass components. Calculations of the calorific values for biomass samples using the proposed improved method were very close to the experimental values of the calorific value. It has been found that the most preferred method of waste disposal is the burning of pellets, their waste plant biomass and polyolefins, since this combustion method provides more high calorific value and increased thermal energy density than a single combustion of only biomass and is accompanied by a smaller amount Carbon dioxide in comparison with the separate burning of only waste polyolefins.

Keywords: biopolymers, biomass, chemical structure, elemental composition, composition, heat of combustion; Calculation methods, calorimetry.

\section{References}

1. Ioelovich M. Advance in Energy, 2014, vol. 2, no. 1, pp. 15-20.

2. Energy recover from waste. Report of New Energy Co. [Electronic resource]. URL: http://www.newenergycorp.com.au/what-we-do/waste-hierarchy. New Energy, West Perth, 2016.

3. Vargas-Moreno J.M., Callejón-Ferrea A.J., Pérez-Alonsoa J., Velázquez-Martí B. Renewable and Sustainable Energy Reviews, 2012, vol. 16, pp. 3065-3083.

4. Suris A.L. Chem. Pertol. Eng., 2007, vol. 43, no. 1-2, pp. 20-21.

5. Maksimuk Iu.V., Kruk V.S., Antonova Z.A., Ponomarev D.A., Sushkova A.V. Lesnoi zhurnal, 2016, no. 6, pp. $110-121$. (in Russ.).

6. Parikh J., Channiwala S.A., Ghosal G.K. Fuel., 2005, vol. 84, pp. 487-494.

7. Huggett C. Fire and Mater, 1980, vol. 4, pp. 61-65.

8. Babrauskas V. Heat Release in Fires, New York: Elsevier, 1992, ch. 8, pp. 251-255.

9. Walters R.N., Lyon R.E., Hackett S.M. Fire and Mater, 2000, vol. 24, pp. 1-13.

10. Willfor S., Sjoholm R., Laine C., Roslund M., Hemming J., Holmbom B. Carbohydrate Polym., 2003, vol. 52, pp. $175-187$.

11. Dubtsova G.N., Kolpakova V.V., Nechaev P.P. Ispol'zovanie belkovykh produktov iz pshenitsy v pishchevykh proizvodstvakh. [Use of protein products from wheat in food production]. Moscow, 1992, 40 p. (in Russ.).

12. Holloway P.J. Phytochemistry, 1983, vol. 22, no. 2, pp. 495-502.

13. Sluiter J.B., Ruiz R.O., Scarlata C.J., Sluiter A.D., Templeton D.W. J Agric. Food Chem., 2010, vol. 58, no. 16, pp. 9043-9053.

14. Ioelovich M. J. Basic Appl. Res. Int., 2016, vol. 16, no. 2, pp. 96-103.

15. Goldberg R.N., Schliesser J., Mittal A. J. Chem. Thermodyn., 2015, vol. 81, pp. 184-226.

16. Kabo G.J., Voitkevich O.V. Blokhin A.V. J. Chem. Thermodyn., 2013, vol. 59, pp. 87-93.

Received December 4, 2016 